\title{
Great tit (Parus major) breeding in fire-prone oak woods: differential effects of post-fire conditions on reproductive stages
}

\author{
Enrico Bellia ${ }^{\mathrm{A}}$, Daniela Campobello ${ }^{\mathrm{A}, \mathrm{B}}$ and Maurizio Sarà ${ }^{\mathrm{A}}$ \\ A University of Palermo, Department of Environmental Biology and Biodiversity, \\ Via Archirafi 18, I-90123 Palermo, Italy. \\ ${ }^{\text {B } C o r r e s p o n d i n g ~ a u t h o r . ~ E m a i l: ~ d a n i e l a c a m p o b e l l o @ h o t m a i l . c o m ~}$
}

\begin{abstract}
Wildfires negatively affect the overall reproductive success of several woodland avian species, but there is scarce information about which stages of the nesting cycle are specifically affected. We conducted a 3-year study to identify the effects of fire on the reproductive parameters of the great tit (Parus major) and the survival of its nests at different stages of the nesting cycle. We recorded the occupancy rate, clutch and brood size, hatching, fledging and nesting success in nest boxes placed on study plots with different post-fire age. By examining the post-fire succession, we analysed the survival of eggs and nestlings under predation risks. As the forest matured after a wildfire, tits occupied more nest boxes and laid more eggs that suffered less predation than in earlier successional stages. Although the incubation fate improved at each step of succession, the conditions to fully raise nestlings seemed to be suitable only in the oldest woods. Our findings indicate that the population dynamics of a reputed generalist avian species may be affected by fire. Furthermore, the effects of wildfires on stage-specific reproductive parameters show that an avian species that inhabits woodlands regains its full productivity only when its habitat has completely recovered from fire.
\end{abstract}

Additional keywords: disturbance event, Mediterranean, nest survival, successional stage, wildfire effects.

\section{Introduction}

Avian communities and biodiversity undergo profound changes after a fire. Species typical of open habitats, for example, have increased foraging opportunities, which can, in turn, show reproductive advantages (Saab et al. 2007). Likewise, in conifer forests, wood-foraging birds are more abundant in recently burned stands (Hutto 1995; Hoyt and Hannon 2002; Nappi et al. 2010), particularly abundant in saproxylic insects, their preferred prey (Nappi et al. 2003, 2010). In fact, recently burned boreal forests provide optimal foraging and nesting conditions for fire specialists such as the black-backed woodpecker (Picoides arcticus; Nappi and Drapeau 2009).

In contrast, some woodland species may continue to breed with suboptimal success after a fire (Meehan and George 2003; Bellia 2005; Sarà et al. 2006). Wildfires affect the population dynamics and distribution of these avian species by decreasing the area of suitable habitat and their optimal trophic resources and by producing more habitat patches with an increased amount of edges (Stuart-Smith et al. 2002; Maina and Jackson 2003; Adeney et al. 2006). Species that nest after a fire have been found to show poor reproductive performance because of their reduced productivity and lower nest success or survival (Kochert et al. 1999; Humple and Holmes 2006). These parameters describe the global effects of fire on reproduction, but they do not distinguish whether they negatively influence only one or all the stages of the nesting cycle. Nest failure can be caused by several potential events, including predation on eggs and nestlings, food deprivation and nest desertion (Martin 1995;
Barlow and Peres 2004). It remains unclear whether the reduced productivity recorded in burned areas is due to variation in clutch size, unhatched eggs or other causes occurring at different nesting stages.

In general, studies have focussed only on specialist species with conservation status of concern (Vierling and Lentile 2006; La Puma et al. 2007), which may result in a lack of a holistic judgement for understanding the effects of fire on avian communities (Leidolf and Bissonette 2009). Generalist species also play an important role in the avian community. Nevertheless, the effect of fire on their population dynamics remains poorly studied (Deng and Gao 2005). In Mediterranean habitats, the great tit is a generalist forest species (Massa et al. 2004; Gil-Tena et al. 2007) that also inhabits gardens and parks (Cramp 1992). Nour et al. (1998) indicated that its reproductive success is not affected by forest fragmentation and implied that this species is able to respond adaptively to various conditions. Other evidence, however, suggested that great tits have more specific needs than previously thought (Herrando and Brotons 2002; Bellia 2005). We chose the great tit as a model of generalist forest species to investigate their adaptability to post-fire contexts.

In this study, we tested whether the nest stages were differentially affected by the post-fire conditions by investigating the reproductive parameters of the great tit (Parus major) in a fireprone area. Our objective was to test whether the time since fire was related to (i) occupancy rate; (ii) clutch and brood size; (iii) hatching, fledging and nest success; and (iv) survival of the 
nest during the different stages of the nesting cycle of great tits breeding in a fire-prone Mediterranean mixed forest.

\section{Materials and methods}

\section{Study area}

This study was conducted between 2003 and 2005 in the Madonie Mountains, a regional park of $\sim 40000$ ha, located in northern Sicily (Italy, $37^{\circ} 50^{\prime} \mathrm{N}, 14^{\circ} 05^{\prime} \mathrm{E}$ ). Here, the vegetation is arranged along several altitudinal belts, from high-altitude (1300-2000 m above sea level) beech forests (AnthriscoFagetum aceretosum) to (80-800 m above sea level) mixed evergreen oak wood (Erico-Quercion ilicis, Pignatti 1997; Raimondo 1998) on lower slopes. The woodlands are dominated by cork oaks (Quercus suber) intermingled with deciduous oaks ( $Q$. virgiliana, $Q$. amplifolia and $Q$. delechampi), ashes (Fraxinus ornus) and pines (Pinus pinea). The understorey is mainly composed of Erica arborea, Arbutus unedo, Cistus creticus, C. monspeliensis, $C$. salvifolius and Calicotome infesta (Raimondo 1998).

From 1980 to 2002, human-caused fires periodically affected a total of $28 \%$ (27210 ha) of the area (within and outside the park). We identified five 100-ha wood sites of Erico-Quercion ilicis that had been affected by fire at different times and, as such, represented different post-fire ages along the succession: two plots burned in 2001, one in 2000, one in 1998 and one in 1993. We identified, as a control, another 100-ha plot that had remained unburned for at least 50 years, which is the time interval of spontaneous fires occurring in similar dry ecosystems of the Mediterranean Climate Zone (Sousa 1984). The post-fire age of each plot was determined from personal records and inquiries directed to forestry officers and local people. We detected a homogeneous vegetation cover and composition among plots within each post-fire age. All plots had a N-NW exposure, were separated by ridges and were $1 \mathrm{~km}$ distant from each other.

\section{Sampling design}

Studies of the effect of time since fire have been penalised either by the assumption that differently burned plots represent a unique post-fire succession (synchronic model; Adeney et al. 2006) or by impractical long-term sampling on the same plots (diachronic model; Moreira et al. 2001; Adeney et al. 2006). In the present study, we used a mixed approach, the diachrosynchronic model, which uses both models by sampling the same areas in consecutive years and areas with different postfire ages (Prodon and Pons 1993; Sarà et al. 2006). This approach presents some disadvantages because it cannot take into account the heterogeneity of different areas, their past fire histories and possible variation in species detection in the years of study. However, the diachro-synchronic model has been shown to be more reliable for students and researchers interested in the ecological response of ecosystems after fire. This mixed model is a useful compromise for reconstructing a secondary succession and provides more insight on the long-term effects of fire (Prodon and Pons 1993; Sarà et al. 2006). Because of the difficulties in finding more than one homogeneous plot burned between 1993 and 2000, we pooled the data from the sere of $5.5-11.5$ years to the median sere of 8.5 years. Table 1
Table 1. Replication of the dataset in terms of the number of years and plots within each post-fire age, according to the diachro-synchronic design applied to test the effect of time since last fire on the reproductive success and nesting survival of great tits in the Madonie Regional Park (Italy)

\begin{tabular}{lcc}
\hline Post-fire age (years) & $n$ of plots & $n$ of years \\
\hline 1.5 & 2 & 2 \\
2.5 & 3 & 3 \\
3.5 & 3 & 3 \\
4.5 & 2 & 2 \\
8.5 & 2 & 5 \\
$>50$ & 1 & 3 \\
\hline
\end{tabular}

summarises the replication of the dataset in terms of the number of post-fire ages and plots sampled in the 3 years of the study.

Reproductive variables, nesting survival and statistical analyses

We monitored nests of great tits in mixed-oak woodlands from 2003 to 2005 . In each experimental plot, we placed $\sim 30$ nest boxes, $20 \mathrm{~m}$ distant from each other. Starting from the last week of March until the end of June, we visited each box every 7-8 days. The causes of nest failure were classified into predation - when, between nest checks, we recorded some kind of loss in nest content - and nest desertion - when no nest content loss was recorded and the eggs were cold and unhatched from the last nest check. We did not record unhatched eggs and starved nestlings. If a box was found with a completed clutch, we back-dated the first day of laying by using an incubation time of 13 days from hatching (Cramp 1992).

From the data collected, we quantified the following variables: occupancy rate (the proportion of nest boxes occupied out of the total number available), clutch and brood size, hatching success (the proportion of eggs hatched out of the total number of eggs laid), fledging success (the proportion of young fledged out of the total number of nestlings hatched) and nesting success (the proportion of young fledged out of the total number of eggs laid).

To determine whether post-fire age affected nest survival, we conducted a series of survival analyses by adopting the approach proposed by Mayfield $(1961,1975)$. Tests that are based on final reproductive rates do not take into account the temporal sequence of nest failure and the number of nests potentially available to nest predators (Mayfield 1961). Survival analyses overcome this limitation by making no assumptions about the final fate of each monitored nest (Rotella et al. 2004). We considered 'survived nests' as those where no eggs or nestlings went missing during the nest-monitoring period. Because of the low number of nest-desertion events, they were not statistically analysable (see Results), and we quantified nest survival due to predation only. Similarly to the methods adopted by studies of population demography (Boal et al. 2005) and dynamics (Woodworth 1999), we considered the nest predation event as having occurred on the day of the midpoint between the two last nest checks. We determined the survival from predation separately for eggs and nestlings using the Kaplan-Meier product limit, where the data were arranged according to survival time 
Table 2. Within the total number of great tit nests recorded in the Madonie Regional Park (Italy) per post-fire age, the numbers of successful and failed nests and the causes of their failure are indicated

Percentages in parentheses are computed from the total number of nests

\begin{tabular}{|c|c|c|c|c|c|c|c|}
\hline \multirow{2}{*}{$\begin{array}{l}\text { Post-fire age } \\
\text { (years) }\end{array}$} & \multirow{2}{*}{$\begin{array}{c}\text { Total number } \\
\text { of nests }\end{array}$} & \multirow{2}{*}{$\begin{array}{c}\text { Successful } \\
\text { nests } \\
n(\%)\end{array}$} & \multirow{2}{*}{$\begin{array}{c}\text { Failed } \\
\text { nests } \\
n(\%)\end{array}$} & \multicolumn{4}{|c|}{ Failed nests } \\
\hline & & & & $\begin{array}{c}\text { Nests with egg } \\
\text { predation events } \\
n(\%)\end{array}$ & $\begin{array}{c}\text { Nests with nestling } \\
\text { predation events } \\
n(\%)\end{array}$ & $\begin{array}{c}\text { Abandoned } \\
\text { nests } \\
n(\%)\end{array}$ & $\begin{array}{c}\text { Nests with uncertain } \\
\text { failure cause } \\
n(\%)\end{array}$ \\
\hline 2.5 & 6 & $1(17)$ & $5(83)$ & $2(33)$ & $2(33)$ & $1(17)$ & $0(0)$ \\
\hline 3.5 & 4 & $0(0)$ & $4(100)$ & $2(50)$ & $0(0)$ & $1(25)$ & $1(25)$ \\
\hline 4.5 & 8 & $2(25)$ & $6(75)$ & $3(38)$ & $1(13)$ & $0(0)$ & $2(25)$ \\
\hline 8.5 & 34 & $14(41)$ & $20(59)$ & $3(9)$ & $11(32)$ & $2(6)$ & $4(12)$ \\
\hline$>50$ & 24 & $17(71)$ & $7(29)$ & $0(0)$ & $5(21)$ & $0(0)$ & $2(8)$ \\
\hline
\end{tabular}

Table 3. Occupation rates and mean ( \pm s.e.) reproductive values of great tit nests recorded per post-fire age in the Madonie Regional Park (Italy)

\begin{tabular}{|c|c|c|c|c|c|c|c|c|c|c|c|c|}
\hline \multirow{2}{*}{$\begin{array}{l}\text { Post-fire age } \\
\text { (years) }\end{array}$} & \multicolumn{2}{|c|}{ Occupation rate } & \multicolumn{2}{|c|}{ Clutch size } & \multicolumn{2}{|c|}{ Brood size } & \multicolumn{2}{|c|}{ Hatching success } & \multicolumn{2}{|c|}{ Fledging success } & \multicolumn{2}{|c|}{ Nest success } \\
\hline & $n$ & Frequency & $n$ & Mean \pm s.e. & $n$ & Mean \pm s.e. & $n$ & Mean \pm s.e. & $n$ & Mean \pm s.e. & $n$ & Mean \pm s.e. \\
\hline 2.5 & 30 & 0.30 & 5 & $8.20 \pm 0.20$ & 5 & $3.00 \pm 1.84$ & 5 & $0.38 \pm 0.23$ & 1 & 1.00 & 5 & $0.20 \pm 0.20$ \\
\hline 3.5 & 33 & 0.15 & 3 & $7.33 \pm 0.88$ & 2 & $2.50 \pm 2.50$ & 2 & $0.42 \pm 0.42$ & 1 & 0.00 & 1 & 0.00 \\
\hline 4.5 & 34 & 0.26 & 6 & $7.67 \pm 0.42$ & 6 & $5.00 \pm 1.61$ & 6 & $0.67 \pm 0.21$ & 3 & $0.67 \pm 0.33$ & 5 & $0.40 \pm 0.24$ \\
\hline 8.5 & 98 & 0.42 & 25 & $7.68 \pm 0.38$ & 23 & $6.22 \pm 0.56$ & 23 & $0.84 \pm 0.06$ & 20 & $0.61 \pm 0.10$ & 23 & $0.50 \pm 0.09$ \\
\hline$>50$ & 44 & 0.68 & 24 & $9.13 \pm 0.38$ & 24 & $8.08 \pm 0.50$ & 24 & $0.88 \pm 0.03$ & 22 & $0.79 \pm 0.08$ & 24 & $0.65 \pm 0.08$ \\
\hline
\end{tabular}

and predation events relative to each nest. We then tested whether time since fire was a valid predictor of nest survival time by running Cox regressions (Cox 1972; Cox and Oakes 1984).

To control whether other factors had a potential effect on the reproductive parameters and nest failure rates, we conducted other survival analyses by treating the study years and plots as independent variables and the number of days of egg and nestling survival as the dependent variable. In this case, to compare nest survival between discrete groups of years and plots, we used the Gehan-Wilcoxon and log-rank tests (Fox 2001), which relate the dependent variable (i.e. nest survival time) to categorical predictors (i.e. year and plot). Within each study year, the number of surviving and non-surviving nests allowed testing of the effect of each year. However, because of the absence of non-surviving nests in three plots, we could perform analyses of egg survival only in plots burned in 1993, 2000 and 2001 and on nestling survival in plots burned in 1950, 1993 and 2000.

Finally, we ran linear regressions (Zar 1999) to test the relationship between post-fire age and occupancy rate, clutch and brood size and nesting success. The linear regressions also allowed testing of the relationship between post-fire age and desertion events. Our sample size did not, however, allow running linear regression analyses within each year and plot. All analyses were conducted using Statistica 6.0 (Statsoft Inc., Tulsa, OK, USA, 2001).

\section{Results}

We found a total of 94 nest boxes occupied during the 3-year study. In 16 nests (17\%), only new nest material was added and
Table 4. Results of the survival analysis regressions, which tested the effect of year, plot (Gehan-Wilcoxon and log-rank tests) and post-fire age (Cox test) on the survival time of eggs and nestlings of great tit nests in the Madonie Regional Park (Italy)

Study years were 2003 to 2005 . For egg survival test, plots burned in 1993 , 2000 and 2001; for nestling survival test, plots burned in 1950, 1993 and 2000. All post-fire ages, from 2.5 to 50 years. Probability significances are: ns, $P>0.05 ; *, P \leq 0.05 ; * *, P \leq 0.01 ; * *, P \leq 0.001$

\begin{tabular}{lcccccccc}
\hline Effect of: & \multicolumn{4}{c}{ Egg survival } & \multicolumn{4}{c}{ Nestling survival } \\
& $n$ & $\chi^{2}$ & d.f. & $P$ & $n$ & $\chi^{2}$ & d.f. & $P$ \\
\hline Year & 74 & 5.63 & 3 & ns & 56 & 2.15 & 3 & ns \\
Plot & 46 & 5.02 & 3 & ns & 49 & 3.40 & 3 & ns \\
Post-fire age & 74 & 13.68 & 1 & $* * *$ & 56 & 2.46 & 1 & ns \\
\hline
\end{tabular}

no egg laying was recorded and, therefore, these nests were not taken into account for subsequent analyses. For another 10 nests $(11 \%)$, it was not possible to determine the cause of failure, and therefore, they were not taken into account in quantifying the clutch or brood size of the population. Survival analyses were conducted on 74 nests during the incubation and 56 during the nestling stages. For the linear regression analyses, from 47 to 63 nests were available to quantify the reproductive and nest failure rates and the clutch and brood size in the sites with different post-fire ages (Tables 2, 3).

The study year and plot did not affect the survival of both eggs and nestlings from predation (Table 4). At the end of the incubation stage and across the sere, the cumulative proportion of nests surviving egg predation was $0.85 \pm 0.04$ (Kaplan-Meier product limit, $n=74$ ). The Cox regressions showed that 


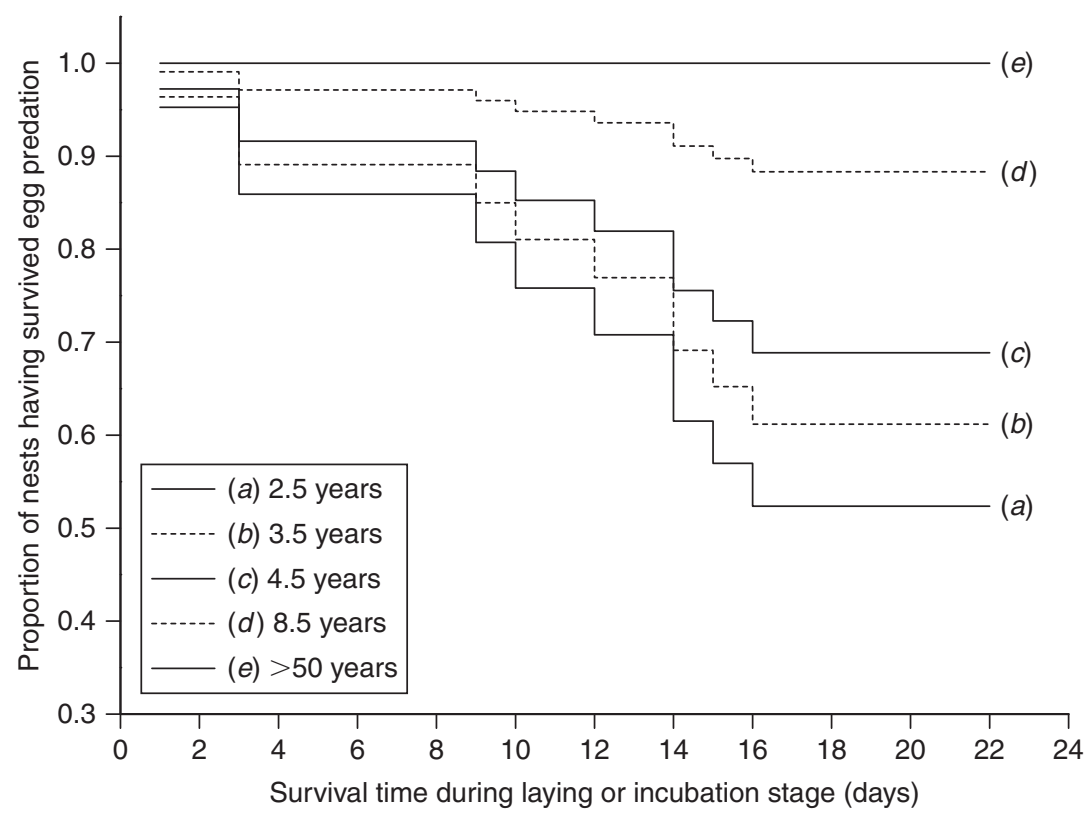

Fig. 1. Survival curves of great tit nests in different post-fire successional stages. Cox regressions revealed that time since last fire was a significant predictor of whether or not eggs survived predation over time.

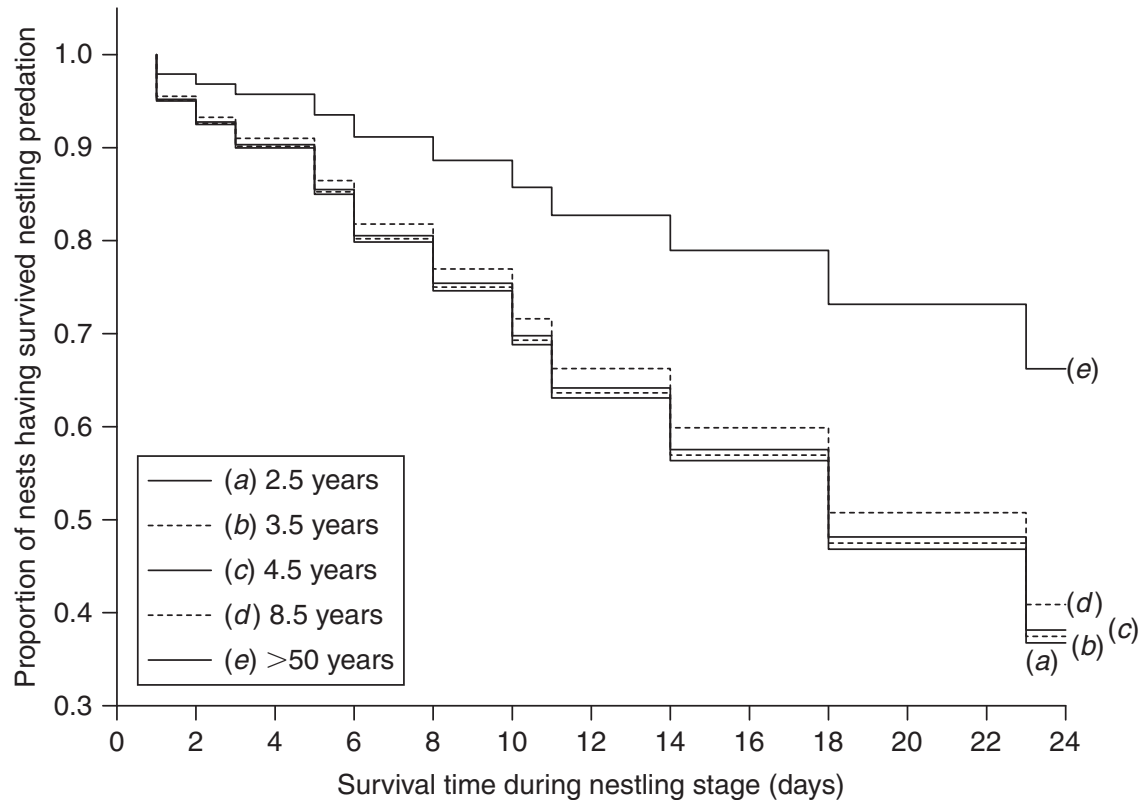

Fig. 2. Survival curves of great tit nests in different post-fire successional stages. Cox regressions revealed that time since last fire was not a significant predictor of whether or not nestlings survived predation over time. Survival of nests that escaped nestling predation was, however, significantly different between all the burned plots and the plot that remained unburned for more than 50 years.

post-fire age was a predictor of the nest surviving egg predation (Table 4). This result indicates that egg survival improved significantly at each temporal step along the succession, reaching its maximum in the unburned plot (Fig. 1).

At the end of the nestling stage and across the succession, the cumulative proportion of nests surviving nestling predation was
$0.48 \pm 0.12$ (Kaplan-Meier product limit, $n=56$ ). In this case, the post-fire age was not a predictor of the nest surviving nestling predation, and thus nestlings had a similar probability to fledge regardless of the stage of succession in which they were raised (Table 4). However, by examining the nest survival curves predicted by Cox regressions (Fig. 2), we suspected that 
Table 5. Linear regression coefficients and probabilities of the effect of post-fire age on the occupancy, reproductive and nest failure values of the great tit in Madonie Regional Park (Italy)

Probability significances are: ns, $P>0.05 ; *, P \leq 0.05 ; * *, P \leq 0.01 ; * * *$,

$$
P \leq 0.001
$$

\begin{tabular}{lcc}
\hline Post-fire age compared with & $R^{2}$ & $P$ \\
\hline Occupation rate & 0.077 & $*$ \\
Clutch size & 0.138 & $* *$ \\
Brood size & 0.192 & $* * *$ \\
Hatching success & 0.067 & $*$ \\
Fledging success & 0.043 & $\mathrm{~ns}$ \\
Nesting success & 0.068 & $*$
\end{tabular}

the nests in all burned areas survived less time than those in the area unburned for more than 50 years. Therefore, by grouping the data, we found that nestling survival improved significantly only in the comparison between burned and unburned areas and not among the most recently burned plots (Gehan-Wilcoxon test statistic $=-3.27, P=0.001$, log-rank test statistic $=3.35$, $P=0.001)$.

The occupation rates increased significantly with time since the last fire (Table 5), indicating that a larger number of great tits nested in older succession stages. On these plots, the regression results revealed that clutch and brood size increased significantly with post-fire age (Table 5), and thus the great tits laid more eggs and raised more nestlings in areas less disturbed by fire. The regression analyses confirmed the results of the previous analyses by showing that fewer eggs, but not fewer nestlings, survived in recently burned plots than in older successions, which probably influenced the significant trend of the final nesting success (Table 5).

\section{Discussion}

In the Mediterranean forest of the Madonie Regional Park, great tits nested preferentially in more mature wood plots, where they achieved higher reproductive success, as they laid larger clutches and suffered less egg predation than conspecifics nesting in early succession areas. The overall nesting success increased with time since last fire; thus, great tits fledged more young in areas undisturbed by fire for a longer time. As desertion played little role in reducing the clutch size, hatching success was mostly affected by predation pressure on eggs, as shown by the greater egg survival in more mature forest plots. Indeed, eggs had a significantly higher survival rate at each step of the temporal sere. In contrast, fledging success did not relate to post-fire age. Again, predation was the major cause of brood reduction. In this case, the survival of nestlings did not increase significantly across the early and intermediate sere, but did only in the oldest mature oak woods. Specifically, in the intermediate sere, the eggs had a higher survival rate, whereas nestlings suffered the same predation rate as that occurring in the early succession areas.

Clutch size variation in great tits has been largely studied as a reproductive variable that is strictly dependent on specific factors. Some authors have suggested that great tits and many other avian species adjust their clutch to a size by tuning it to predation risk (Martin 1995; Doligez and Clobert 2003; Doligez et al. 2008). This is consistent with our results in the Madonie Mountains, where the higher predation rate may have influenced the reduced clutch and, in turn, the brood size observed in the early succession plots.

The heavier predation pressure on recently burned areas may also explain the low occupancy rate recorded on these plots. Nest spacing has been interpreted as the only effective nest defence response of the great tit (Krebs 1971), which is consistent with the slower post-fire recovery shown by some endangered avian species (Lindenmayer et al. 2009).

The mechanism that underlies the greater survival of eggs, and not of nestlings, across the successional gradient of the Madonie Mountains remains elusive. One of the effects of wildfires is to turn a continuum habitat into a collection of small patches (Deng and Gao 2005). Moreover, edge effects have been found to be the principal cause for the increase in nest predation in areas mostly affected by human-induced habitat fragmentation (Hartley and Hunter 1998; Githiru et al. 2005). Thinned vegetation cover and proximity to new edges are the causes that explain a reduced productivity of avian species (Flaspohler et al. 2001; Manolis et al. 2002), including secondary cavity nesters (Huhta and Jokimäki 2001; Vierling and Lentile 2006). Our results showed that the gradual recovery of burned plots allowed great tit eggs to survive until hatching, but this recovery was insufficient to prevent predation on nestlings. Only the complete recovery of a mature forest allowed the young to survive significantly longer. Partial recovery of the vegetation in the intermediate sere might have been sufficient for great tits to escape predator detection in the early stage of nesting, but it might not have been sufficient when nestling begging and smell and parental feeding activity made a nest more conspicuous to predators.

In our study site, pine martens (Martes martes) and common rats (Rattus rattus) have been observed to predate on both eggs and nestlings of great tits. The rats, in particular, occupied more nest boxes in post- rather than in pre-fire areas (occupation rate: 0.25 v. 0.01 respectively), whereas they were completely absent in the unburned area (Milazzo 2006; M. Sarà, unpubl. data). However, we are unaware of what proportion of great tit eggs and nestlings comprises the diet of these predators, whether they change their prey throughout the nesting season and whether there are seasonal fluctuations in the abundance of these predators among the different succession sere.

In fragmented areas, community biodiversity declines (Barlow and Peres 2004; Adeney et al. 2006; Gil-Tena et al. 2008), and the few nesting species left might be under higher predation pressure, which was formerly distributed across a larger number of potential prey types (Humple and Holmes 2006). Previous results (Bellia 2005; Sarà et al. 2006) showed that burned areas experienced a decrease in vertebrate community richness, indicating that nester species can be subject to changed predator dynamics and preferences. Further studies that address the seasonal changes in prey availability of generalist predators would shed more light on the differential predation of eggs and nestlings shown by this study.

Our results both concur and disagree with previous studies where habitats that underwent human-induced disturbance events showed that cavity nesters (Matthysen and Adriaensen 1998; Huhta and Jokimäki 2001; Vierling and Lentile 2006; 
Saab et al. 2007) and other species (Flaspohler et al. 2001; Manolis et al. 2002; Meehan and George 2003) experience poorer reproductive performance. Because these studies quantified the overall parameters of reproductive success, it was unclear which percentage of the variation in productivity was due to variation in clutch size, predation, or other factors potentially influencing nesting cycle fates. By analysing each reproductive parameter from nest survival to hatching and fledging, we were able to dissect the effects of time since last fire and to pinpoint the variables or the nesting stage that were specifically affected.

It has been assumed that disturbed areas may offer populations of coloniser and specialist species contrasting conditions, where the former can either grow or remain stable whereas the latter can decrease their productivity and decline (Barlow and Peres 2004; Bellia 2005; Adeney et al. 2006; Sarà et al. 2006). Our results showed that fire affected the overall reproductive performance of great tits as they nested in small numbers in recently burned areas and laid smaller clutches that suffered more intense predation. Although we could not examine the effect of years and plots on reproductive parameters, these factors did not affect nest survival, indicating that time since the last fire was the only factor that played an important role in the fate of great tit nests. An increase in the sample size would, however, corroborate our findings, which are consistent with less harsh environmental pressures along the post-fire sere during nesting territory establishment and, later, during egg production and laying.

\section{Acknowledgements}

We are indebted to our dear friend Walter Falletta, too prematurely departed, for his precious contribution to the field work. We also thank Andrea Milazzo and Serena Di Giorgi who helped with data collection in the field. We thank two anonymous reviewers and the Associate Editor for constructive comments on the manuscript. Funding was provided by the Scientific Research Grants (ex-quota 60\%) of the University of Palermo for the years 2001-2004.

\section{References}

Adeney JM, Ginsberg JR, Russell GJ, Kinnaird MF (2006) Effects of an ENSO-related fire on birds of a lowland tropical forest in Sumatra. Animal Conservation 9, 292-301. doi:10.1111/J.1469-1795.2006. 00035.X

Barlow J, Peres CA (2004) Avifaunal responses to single and recurrent wildfires in Amazonian forests. Ecological Applications 14, 1358-1373. doi:10.1890/03-5077

Bellia E (2005) Diversità e struttura dell'avifauna in una successione post incendio di bosco meso-mediterraneo. Avocetta 29, 75-84.

Boal CW, Andersen DE, Kennedy PL (2005) Productivity and mortality of northern goshawks in Minnesota. Journal of Raptor Research 39, 222-228.

Cox DR (1972) Regression models and life-tables. Journal of the Royal Statistical Society. Series B. Methodological 34(2), 187-220.

Cox DR, Oakes D (1984) 'Analysis of Survival Data.' (Chapman and Hall: New York)

Cramp S (Ed.) (1992) 'The Birds of the Western Palearctic. Vol. VI. Warblers.' (Oxford University Press: London, UK)

Deng WH, Gao W (2005) Edge effects on nesting success of cavity-nesting birds in fragmented forest. Biological Conservation 126, 363-370. doi:10.1016/J.BIOCON.2005.06.013
Doligez B, Clobert J (2003) Clutch size reduction as a response to increased nest predation rate in the collared flycatcher. Ecology 84, 2582-2588. doi: $10.1890 / 02-3116$

Doligez B, Berthouly A, Doligez D, Tanner M, Saladin V, Bonfils D, Richner H (2008) Spatial scale of local breeding habitat quality and adjustment of breeding decisions. Ecology 89, 1436-1444. doi:10.1890/ 07-0113.1

Flaspohler DJ, Temple SA, Rosenfield RN (2001) Species-specific edge effects on nest success and breeding bird density in a forested landscape. Ecological Applications 11, 32-46. doi:10.1890/1051-0761(2001)011 [0032:SSEEON]2.0.CO;2

Fox GA (2001) Failure-time analysis: studying times to events and rates at which events occur. In 'Design and Analysis of Ecological Experiments'. (Eds SM Scheiner, J Gurevitch) pp. 235-266. (Oxford University Press: New York)

Gil-Tena A, Saura S, Brotons L (2007) Effects of forest composition and structure and bird species richness in a Mediterranean context: implications for forest ecosystem management. Forest Ecology and Management 242, 470-476. doi:10.1016/J.FORECO.2007.01.080

Gil-Tena A, Torras O, Suara S (2008) Relationships between forest landscape structure and avian species richness in NE Spain. Ardeola 55, 27-40.

Githiru M, Lens L, Cresswell W (2005) Nest predation in a fragmented Afrotropical forest: evidence from natural and artificial nests. Biological Conservation 123, 189-196. doi:10.1016/J.BIOCON.2004.11.006

Hartley MJ, Hunter ML, Jr (1998) A meta-analysis of forest cover, edge effects, and artificial nest predation rates. Conservation Biology 12, 465-469. doi:10.1046/J.1523-1739.1998.96373.X

Herrando S, Brotons L (2002) Forest bird diversity in Mediterranean areas affected by wildfires: a multi-scale approach. Ecography 25, 161-172. doi: 10.1034/J.1600-0587.2002.250204.X

Hoyt JS, Hannon SJ (2002) Habitat associations of black-backed and threetoed woodpeckers in the boreal forest of Alberta. Canadian Journal of Forest Research 32, 1881-1888. doi:10.1139/X02-109

Huhta E, Jokimäki J (2001) Breeding occupancy and success of two holenesting passerines: the impact of fragmentation caused by forestry. Ecography 24, 431-440. doi:10.1034/J.1600-0587.2001.D01-199.X

Humple DL, Holmes AL (2006) Effects of a fire on a breeding population of loggerhead shrikes in sagebrush steppe habitat. Journal of Field Ornithology 77, 21-28. doi:10.1111/J.1557-9263.2006.00004.X

Hutto RL (1995) Composition of bird communities following standreplacement fires in northern Rocky Mountain (USA) conifer forests. Conservation Biology 9, 1041-1058. doi:10.1046/J.1523-1739.1995. 9051033.X-I1

Kochert MN, Steenhof K, Carpenter LB, Marzluff JM (1999) Effects of fire on golden eagle territory occupancy and reproductive success. Journal of Wildlife Management 63, 773-780. doi:10.2307/3802790

Krebs JR (1971) Territory and breeding density in the great tit, Parus major L. Ecology 52, 3-22.

La Puma DA, Lockwood JL, Davis MJ (2007) Endangered species management requires a new look at the benefit of fire: the Cape sable seaside sparrow in Everglades ecosystem. Biological Conservation 136, 398-407. doi:10.1016/J.BIOCON.2006.12.005

Leidolf A, Bissonette JA (2009) The effects of fire on avian communities: spatio-temporal attributes of the literature 1912-2003. International Journal of Wildland Fire 18, 609-622. doi:10.1071/WF08019

Lindenmayer DB, Macgregor C, Wood JT, Cunningham RB, Crane M, Michael D, Montague-Drake R, Brown D, Fortescue M, Dexter N, Hudson M, Gill AM (2009) What factors influence rapid post-fire site re-occupancy? A case study of the endangered eastern bristlebird in eastern Australia. International Journal of Wildland Fire 18, 84-95. doi:10.1071/WF07048

Maina GG, Jackson WM (2003) Effects of fragmentation on artificial nest predation in a tropical forest in Kenya. Biological Conservation 111, 161-169. doi:10.1016/S0006-3207(02)00259-8 
Manolis JC, Andersen DE, Cuthbert FJ (2002) Edge effect on nesting success of ground-nesting birds near regenerating clearcuts in a forestdominated landscape. Auk 119, 955-970. doi:10.1642/0004-8038(2002) 119[0955:EEONSO]2.0.CO;2

Martin TE (1995) Avian life history evolution in relation to nest sites, nest predation, and food. Ecological Monographs 65, 101-127. doi:10.2307/ 2937160

Massa B, Lo Valvo F, Margagliotta B (2004) Adaptive plasticity of blue tits (Parus caeruleus) and great tits (Parus major) breeding in natural and semi-natural insular habitats. Italian Journal of Zoology 71, 209-217. doi:10.1080/11250000409356574

Matthysen E, Adriaensen F (1998) Forest size and isolation have no effect on reproductive success of Eurasian nuthatches (Sitta europaea). Auk 115, 955-963.

Mayfield H (1961) Nesting success calculated from exposure. Wilson Bulletin 73, 255-261.

Mayfield HF (1975) Suggestions for calculating nest success. Wilson Bulletin 87, 456-466.

Meehan TD, George TL (2003) Short-term effects of moderate- to highseverity wildfire on a disturbance-dependent flycatcher in northwest California. Auk 120, 1102-1113. doi:10.1642/0004-8038(2003)120 [1102:SEOMTH]2.0.CO;2

Milazzo A (2006) La perturbazione da incendio nella comunità di vertebrati terrestri dei boschi Mediterranei. $\mathrm{PhD}$ dissertation, Università di Palermo, Italy.

Moreira F, Ferreira PG, Rego FC, Bunting S (2001) Landscape changes and breeding bird assemblages in north-western Portugal: the role of fire. Landscape Ecology 16, 175-187. doi:10.1023/A:1011169614489

Nappi A, Drapeau P (2009) Reproductive success of the black-backed woodpecker (Picoides arcticus) in burned boreal forests: are burns source habitat? Biological Conservation 142, 1381-1391. doi:10.1016/ J.BIOCON.2009.01.022

Nappi A, Drapeau P, Giroux J-F, Savard J-P (2003) Snag use by foraging black-backed woodpeckers (Picoides arcticus) in a recently burned eastern boreal forest. Auk 120, 505-511. doi:10.1642/0004-8038(2003) 120[0505:SUBFBW]2.0.CO;2

Nappi A, Drapeau P, Saint-Germain M, Angers VA (2010) Effect of fire severity on the long-term occupancy of burned boreal conifer forests by saproxylic insects and wood-foraging birds. International Journal of Wildland Fire 19, 500-511. doi:10.1071/WF08109

Nour N, Currie D, Matthysen E, Van Damme R, Dhondt AA (1998) Effects of habitat fragmentation on provisioning rates, diet and breeding success in two species of tit (great tit and blue tit). Oecologia 114, 522-530. doi:10.1007/S004420050476

Pignatti S (1997) 'Ecologia del Paesaggio.' (Unione Tipografico-Editrice Torinese (UTET): Torino)

Prodon R, Pons P (1993) Post-fire bird studies: methods, questions and perspectives. In 'Fire in Mediterranean Ecosystems. Ecosystems Research Reports 5'. (Eds L Trabaud, R Prodon) pp. 332-343. (Commission of the European Communities: Brussels, Belgium)

Raimondo FM (1998) Carta del paesaggio e della biodiversità vegetale della provincia di Palermo. Quaderni di Botanica Ambientale e Applicata 9, $3-160$.

Rotella JJ, Dinsmore SJ, Shaffer TL (2004) Modelling nest-survival data: a comparison of recently developed methods that can be implemented in MARK and SAS. Animal Biodiversity and Conservation 21, 187-205.

Saab VA, Russell RE, Dudley JG (2007) Nest densities of cavity-nesting birds in relation to post-fire salvage logging and time since wildfire. Condor 109, 97-108. doi:10.1650/0010-5422(2007)109[97:NDOCBI] 2.0.CO;2

Sarà M, Bellia E, Milazzo A (2006) Fire disturbance disrupts co-occurrence patterns of terrestrial vertebrates in Mediterranean woodlands. Journal of Biogeography 33, 843-852. doi:10.1111/J.1365-2699.2006.01429.X

Sousa WP (1984) The role of disturbance in natural communities. Annual Review of Ecology and Systematics 15, 353-391. doi:10.1146/ ANNUREV.ES.15.110184.002033

Stuart-Smith K, Adams IT, Larsen KW (2002) Songbird communities in a pyrogenic habitat mosaic. International Journal of Wildland Fire $\mathbf{1 1}$ 75-84. doi:10.1071/WF01050

Vierling K, Lentile L (2006) Red-headed woodpecker nest-site selection and reproduction in mixed ponderosa pine and aspen woodland following fire. Condor 108, 957-962. doi:10.1650/0010-5422(2006)108[957: RWNSAR]2.0.CO;2

Woodworth BL (1999) Modelling population dynamics of a songbird exposed to parasitism and predation and evaluating managemen options. Conservation Biology 13, 67-76. doi:10.1046/J.1523-1739. 1999.97267.X

Zar JH (1999) 'Biostatistical Analysis.' 4th edn. (Prentice Hall: Upper Saddle River, NJ)

Manuscript received 8 November 2009, accepted 28 October 2010 